\title{
Producción jurídica e imaginación global: cartografías urbanas a través de la ley en Barcelona
}

\author{
Pedro LIMÓN LÓPEZ \\ Facultad de Ciencias Políticas y Sociología \\ Universidad Complutense de Madrid \\ Pedro.limon@pdi.ucm.es
}

Recibido: 20-05-12

Aceptado: 22-09-12

\begin{abstract}
RESUMEN
El análisis del espacio público ha sido uno de los elementos más controvertidos en la investigación social y política, fundamentalmente por su ambigüedad y polisemia o, en el mejor de los casos, por una reducción exclusiva a las instituciones del Estado. En el ámbito urbano existen diferentes estudios, procedentes sobre todo de la economía política, que relacionan los cambios del espacio público en (o de) la ciudad con los procesos globales de cambio, tanto en el plano económico como, especialmente, sobre las representaciones de lo urbano a escala global. A través de la Geografía crítica del Derecho, el presente artículo se ocupa de las prácticas normativas concretas que han reformulado la noción del espacio público urbano barcelonés en las dos últimas décadas $\mathrm{y}$, fundamentalmente, cómo a través de la agencia institucional se construye una imaginación geográfica de la ciudad en clave "global, cívica y limpia".
\end{abstract}

Palabras clave: imaginación geográfica; geografía legal; políticas territoriales; higienismo; Barcelona.

\section{Legal production and global imagination: urban cartographies through Law in Barcelona}

\begin{abstract}
Public space analysis has been one of the most controversial issues in social and political research, mainly because of its ambiguity and polysemy or, at best, because it has been reduced to the study of state institutions. In urban fields there are many studies — specially at the level of political economy- which make the link between changes in the public space of (or in) the city and global processes occurring at the economy level or, especially, over urban depictions in a global scale. Through a critical Geography of Law, this paper examines how concrete normative practices have contributed to the reshaping of the very term of public space in Barcelona in the last two decades. Specifically this article is set out to show how a geographical imagination which is based on "global, clean and civic" discursive features of Law takes shape.
\end{abstract}

Key words: geographical imagination; legal geography; territorial politics; hygienism; Barcelona. 


\title{
Produção jurídica e imaginação global: cartografias urbanas através da lei em Barcelona
}

\begin{abstract}
RESUMO
A análise do espaço público tem sido um dos elementos mais controvertidos na pesquisa social e política, fundamentalmente por sua ambiguidade e polissemia ou, no melhor dos casos, por uma redução exclusiva às instituições do Estado. No âmbito urbano existem diferentes estudos, procedentes principalmente da economia política, que relacionam as mudanças do espaço público na (da) cidade com os processos globais de mudança, tanto no plano econômico como, especialmente, sobre as representações do urbano em escala global. Através da Geografia crítica do Direito o presente artigo ocupa-se das práticas normativas concretas que reformularam a noção de espaço público urbano barcelonês nas últimas duas décadas e, especificamente, de como através da agência institucional constrói-se uma imaginação geográfica da cidade em chave "global, cívica e limpa".
\end{abstract}

Palavras chave: imaginação geográfica; geografia legal; políticas territoriais; perspectiva higienista; Barcelona.

REFERENCIA NORMALIZADA

Limón López, Pedro (2012) "Producción jurídica e imaginación global: cartografías urbanas a través de la ley en Barcelona". Geopolitica(s). Revista de estudios sobre espacio y poder, vol. 3, núm. 1, 117-135.

SUMARIO: Introducción: espacio público, ciudad y globalización en Barcelona. 1. Derecho y Geografía política. 2. El civismo global de una nueva Barcelona. 2.1. El "modelo Barcelona": metrópolis global. 2.2. "Barcelona, iponte guapa! (y límpiate)". El retorno al higienismo y el civismo como geografia moral de la ciudad. 2.3. De la higiene a la renovación urbana: territorios encontrados. Conclusión: Barcelona, ¿región de frontera? Bibliografía.

\section{Introducción: espacio público, ciudad y globalización en Barcelona}

En las últimas décadas, las transformaciones llevadas a cabo sobre los ámbitos urbanos han sido uno de los objetos de investigación emergentes, vinculado sobre todo a su importancia como espacios sociales y políticos de relevancia global (Johnston, Taylor y Watts, 2002), y especialmente a su irrupción como nuevas formas ideales o imagen global ${ }^{1}$.

\footnotetext{
${ }^{1}$ Existen diferentes visiones, obviamente. Desde una perspectiva puramente economicista, se ha señalado el peso que tienen las ciudades en el sistema de acumulación global, así como en la producción cultural y en la industria de la imagen (Johnston et al., 2002). Dentro de la Geografía política, destacan los análisis e indicadores de ciudades mundiales desarrollado por el grupo de investigación "Globalización y ciudades mundiales" de la Universidad de Loughborough, así como las diversas visiones de la ciudad global (Brenner, 2004) y, pese al énfasis dado al modo de producción y al régimen de acumulación, los estudios procedentes de la Escuela de la Regulación (Judge et al., 1998). En todo caso, se señala el rol de los ámbitos urbanos,
} 
En el caso de Barcelona, hay una cantidad ingente de estudios acerca de esta ciudad como ejemplo paradigmático en la implementación de políticas públicas vinculadas a un modelo de planificación urbana (Delgado, 2005); en la constitución de imaginarios globales urbanos y reconfiguración del paisaje local a partir de fenómenos de marketing urbano (Degen y García, 2008; Muñoz, 2008, 2010); la promoción de espacios económicos creativos (Martí Costa y Pradel i Miquel, 2012); el análisis de procesos de patrimonialización cultural de la memoria industrial (Checa Artasu, 2007; Tatjer, 2008); o la indagación acerca de las transformaciones que han supuesto para la ciudad los grandes proyectos desarrollados desde finales de los años ochenta y especialmente a partir del proyecto olímpico y del Fórum de las Culturas en 2004 (Borja, 2009; Dot Jutgla et al., 2010).

No obstante, existe una carencia analítica de las relaciones entre el espacio público, la imaginación geográfica ${ }^{2}$ y la elaboración e implementación de ciertas normativas en la región barcelonesa que eluden la importancia de la ley en la geografía urbana. Como se ha dicho (Blomley, 2008: 156-158), ambos elementos son productos sociales y productores de esas mismas relaciones sociales que se producen de forma recíproca, al tiempo que la espacialidad es causa y consecuencia de la producción legal o el espacio funciona como un imaginario para los derechos. Asimismo, se han producido modificaciones legales en relación a los espacios políticos, en la medida en que la prescripción sobre los sujetos (quién) ha ido dando paso a prohibiciones sobre el contexto espacial, sobre dónde (Mitchell y Staeheli, 2005).

La cuestión es qué concepción del mismo produce y es reproducida por qué tipo de espacios públicos y a través de qué regulaciones, por lo cual aquí se analizarán qué prescripciones y normativas se han establecido sobre el espacio urbano a través del análisis de diferentes legislaciones y políticas públicas desarrolladas en Barcelona en los últimos veinte años, período que viene marcado por algunos cambios sociales de creciente importancia.

sobre todo los globalmente considerados, como "modelos o aspiraciones" de las localidades en un contexto de régimen de acceso a los mercados y de promoción urbana (Knox et al., 2003). Desde una vertiente más "socio-cultural", existen visiones que reiteran la posibilidad de innovación que reside en las ciudades, empezando por la misma producción social del espacio (Lefebvre, 1976). La cuestión es ¿̨hasta qué punto puede cuestionarse una noción predominantemente urbana del espacio público desde una visión ideal que concibe las ciudades como entes cerrados, homogéneos, privilegiados, esto es, "modélicos", dentro de la economía global?

${ }^{2}$ La imaginación geográfica es la "sensibilidad hacia la importancia del lugar, el espacio y el paisaje en la formación y conducta de la vida social [...], algo que permite a los individuos reconocer la función del espacio y del lugar en su propia vida, en relación con los espacios que ven a su alrededor, identificar cómo las transacciones entre individuos y entre organizaciones están afectadas por el espacio que las separa [...] juzgar la relevancia de acontecimientos en otros espacios [...] modelar y utilizar el espacio de forma creativa, y apreciar el significado de las formas espaciales creadas por otros" (Johnston et al., 2000: 321). 
La generalización del turismo y de formas de producción y consumo cultural vinculados a los procesos de globalización, ha estado encabezada por diferentes acontecimientos o eventos internacionales de carácter cultural, deportivo o relativo al ocio. En el caso español, la fecha clave en ese sentido fue el año 1992: ese año se firma el Tratado de Maastricht o de la Unión Europea, Sevilla fue sede principal de la Exposición Universal, se celebró el V Centenario de Descubrimiento de América, Madrid fue designada Ciudad europea de la cultura y, sobre todo, Barcelona acogió los Juegos Olímpicos de verano (Tresserras, 2004). La previsión de las autoridades estatales y locales fue el establecimiento de una serie de regulaciones acerca de diferentes aspectos socio-políticos que hasta entonces no habían sido objeto de prescripción legal, o lo habían sido marginalmente, como el patrimonio cultural, los espacios de ocio, las actividades turísticas o los espectáculos públicos.

Al calor de estas regulaciones y como motor de otras nuevas, surgen algunos discursos transculturales en el seno de Estados Unidos y Europa occidental que marcan las posteriores prácticas y representaciones políticas. Elementos como "el civismo, el multiculturalismo, la diversidad cultural, las culturas, la prevención, la (in)seguridad urbana, los problemas sociales, la salud, la sostenibilidad o los espacios de calidad" (Featherstone y Lash, 1999) marcarán en adelante el discurso normativo del espacio público urbano.

A través del prisma de la Geografía legal crítica, este artículo pretende mostrar algunas de las relaciones estructurales existentes entre las normativas institucionales y las representaciones geográficas, así como las principales tendencias generadas en torno al espacio público barcelonés. En el siguiente epígrafe, introduzco el desarrollo de la geografía legal en la Geografía Política, así como la importancia de su uso en el análisis de las configuraciones de los espacios públicos en el contexto de la reestructuración urbana en los últimos veinte años.

Posteriormente, se esbozan algunas de las tendencias que traza el análisis de dichas normativas sobre los espacios públicos y políticos, atendiendo especialmente a las representaciones globales de la ciudad, la agencia institucional a partir del civismo y el higienismo urbano, o las políticas de renovación urbana en Barcelona.

Finalmente, me pregunto qué tipo de paradojas puede generar la reterritorialización del espacio público barcelonés en torno a nuevas regiones de frontera que fragmentarían la ciudad en múltiples espacios orientados al exterior y unificados de manera creciente por una concentración del control y de las decisiones en clave institucional.

\section{Derecho y Geografía política}

El concepto de espacio público ha sido uno de los más controvertidos en Ciencias Sociales (Low y Smith, 2006), pasando de confundirse con las instituciones del Estado (Habermas, 1974; Salcedo y Caicedo, 2008) a su admisión como un término 
ambiguo en el terreno político y urbanístico (Aramburu, 2008). La temprana conexión del concepto con la esfera pública implicaba un nexo con la representación pública que tenía que ver no sólo con la unificación de las dimensiones de expresión política (Pitkin, 1985), sino que estaba conectada con el Estado y el Derecho. Derecho que, debido al principio de seguridad y unidad jurídica, complicaban desligar el espacio público del legal y éstos a su vez del Estado (Poggi, 1977) y, por inferencia, hacía "imposibles" otras representaciones políticas y otros espacios sociales, silenciados y ocultos tras el falaz universalismo liberal (Young, 1990).

Esta visión del espacio público como esfera institucional de representación formal emanaba en buena parte de una visión del mismo centrada en la ciudad y, paradójicamente, fue en estos ámbitos donde recayó buena parte de la crítica al Estado como escala preeminente de los fenómenos políticos ${ }^{3}$.

En el ámbito académico, el giro espacial en Teoría Social resquebrajó la tendencia a establecer separaciones entre la ley, el espacio y la sociedad, y, dentro de la Geografía Política, surgió la Geografía legal crítica como una visión que "desarrolló una lectura muy distinta de la ley, del espacio y de las relaciones mutuas entre ambos" (Gregory et al., 2009: 414).

Formada por distintas perspectivas y corrientes, esta Geografía crítica del Derecho tiene como elemento distintivo el rechazo de la ley y el espacio como entes prepolíticos y separados (Johnston et al., 2000). Desde esta visión, ambas esferas son no sólo complementarias, sino que se solapan entre sí, "examinando cómo el espacio modifica o reforma los efectos de la ley y, simultáneamente, como la ley da forma a las relaciones espaciales" (Martin et al., 2010: 177), centrándose en tres cuestiones: el análisis de los modos a través de los cuales la acción e interpretación legal produce determinados espacios; la naturaleza situada (el Lugar) de la interpretación legal; y en el estudio de las demandas geográficas y representaciones contenidas en el discurso legal (Gregory et al., 2009).

Por otro lado, buena parte de los cambios referidos a las producciones del espacio están relacionados con las transformaciones político-económicas que se llevan a cabo en las ciudades, así como la influencia que tienen la aplicación e interpretación legal sobre la exclusión de determinados grupos sociales (Blomley, 2003, 2010; Dangschat, 2009; Forest, 2001, 2004; Herbert, 2010; Mitchell, 1997, 2003; Mitchell y Heynen, 2009; Staeheli, 2010), por lo cual dicha visión es compatible con muchos de los estudios procedentes de la economía política urbana (Blomley, 2004; Delaney et al., 2010), sobre todo en el estudio de los procesos de globalización (Barkan,

\footnotetext{
${ }^{3}$ La escala es "el nivel de resolución geográfica en que un fenómeno dado es pensado, estudiado y actuado" (cf. Agnew, 1993; cit. en Brenner, 2004: 9). El cuestionamiento de la escala en que pueden desarrollarse los fenómenos sociales y políticos supuso el resquebrajamiento de una perspectiva a-espacial del poder, cierto "sentido común incuestionable" en torno al Estado, haciendo de la escala estatal algo "naturalizado" en la medida en que el espacio se consideraba "neutral" (Agnew y Duncan, 1989).
} 
2011) o, especialmente, con las reflexiones acerca de las nuevas cartografías urbanas desarrolladas en las "ciudades-frontera" y con el análisis de los procesos globales urbanos como productores de regiones de frontera ${ }^{4}$.

Considerando la región de frontera como "un frente pionero orientado hacia el exterior, como punta de lanza de la civilización" (Taylor y Flint, 2002: 179), la geografía crítica del derecho arroja luz acerca de las formas de producción política que estructuran esos modos de segregar la ciudad a partir de proyecciones exteriores y fronterizas de la ciudad, construidas fundamentalmente a través de diferentes fenómenos de gentrificación y renovación urbana ${ }^{5}$.

\section{El civismo global de una nueva Barcelona}

Siguiendo la metodología del análisis crítico del discurso, el estudio se centra en las prácticas de producción política que se producen a partir del discurso legal (Chouliaraki y Fairclough, 1999: 23), estableciéndose por las propias administraciones competentes en materia urbana en las dos últimas décadas ${ }^{6}$.

\footnotetext{
${ }^{4}$ En dicho análisis se sostiene que, producto de la dialéctica entre las dinámicas de globalización y localización, la postmetrópolis moderna carece de límites conceptuales y materiales, lo que a su vez implicaría una remundialización del espacio urbano de modo simultáneo a la segregación de diversos espacios del mismo, haciendo de las ciudades frontera un puesto fronterizo entre dos períodos históricos diferentes (Soja, 2008: 346-347). Como se verá, para los fines de este artículo se utiliza el concepto de región de frontera como concepto que ilustra esa ruptura o fragmentación de imaginaciones geográficas entre el interior y el exterior de la ciudad en clave de Modernidad.

${ }^{5}$ Un proceso de gentrificación es aquel proceso por el cual un espacio urbano en particular, anteriormente despoblado, socialmente erosionado o sin apenas relevancia en las inversiones en la ciudad y configuración espacial, ocupados por clases trabajadoras o pobres, emerge como un espacio con impacto relevante en las prácticas y discursos urbanos, así como en las inversiones desarrolladas de cara a la atracción de consumo, incluyendo la mejora de los entornos físicos o la creación de espacios de ocio, viéndose desplazada la anterior población por rentistas y compradores de clases medias (Harvey, 2007: 377). Si bien la renovación "representa cualquier modernización de parte de un área urbana" (Johnston et al., 2000: 491) y conceptualmente puede desligarse de la gentrificación, ambos procesos van unidos de manera inextricable y, como se verá, son inseparables en la práctica normativa, retroalimentándose mutuamente y fundiéndose como elemento de representación de los proyectos de renovación de la ciudad en general. Ambos procesos ejercen un gran poder simbólico al actuar como metáfora de las transformaciones sociales de la ciudad, además de que son los proyectos los que actúan como imágenes de la ciudad, produciendo representaciones de zonas de transición entre lo conocido y el resto (Smith, 1996).

${ }^{6}$ En la medida en que se considera la imaginación geográfica producida desde el marco institucional, se tienen en cuenta aquellas normativas consideradas urbanas y urbanisticas por las propias administraciones. Véase URL: <http://w3.bcn.es/V61/Home/V61HomeLinkPl/0,2687,200713899_200726005_2,00.html> y $<$ http://w110.bcn.cat/portal/site/Urbanisme> [consultadas el 19 de mayo de 2012] . En este sentido, se han analizado la Ley 22/1998, de 30 de diciembre, de la Carta Municipal de Barcelona; la Ley 31/2010, del Área Metropolitana de Barcelona; la Ley 2/2004, de 4 de junio, de mejora de barrios, áreas urbanas y villas que requieren una atención especial; el Decreto legislativo 1/2010, de 3 de agosto, por el que se aprueba el Texto Refundido de la Ley de urbanismo; el Pla General de Seguretat a Catalunya 2012-2013; la Ley 4/2003, de 7
} 
En la medida en que la hermenéutica crítica permite engarzar texto, contexto histórico y agencia de los diferentes sujetos sociales (Denzin y Lincoln, 2005: 311312), el estudio desarrollado se basa en una visión histórica del discurso legal, así como en el uso de herramientas de categorización retórica ${ }^{7}$.

En la medida en que articula "un repertorio de significados políticos y culturales a través de los cuales los ciudadanos pueden negociar e interactuar entre sí [...], [formando] el modo en que la gente concibe el ámbito político y su lugar en él" (Blomley, 2008: 156-157), el análisis de la normativa se centra en los elementos discursivos que construyen un tipo de "mapeado urbano" producido desde el ámbito institucional. Considerando la imagen cartográfica como "la representación cartográfica estructurada de una información espacial o seleccionada [...] que se convierte en mapa cuando se representa física, virtual o lingüísticamente" (Johnston et al., 2000: 320), se analizan cómo va cambiando la definición y representación del "espacio público", así como los diversos espacios urbanos reconocidos desde la esfera institucional a través de dicha normativa.

Así, el análisis llevado a cabo establece algunas tendencias observadas en torno al discurso legal en dicho período, inferidas desde criterios referidos exclusivamente a recurrencias establecidas desde la implementación institucional, dejando a un

de abril, de Ordenación del Sistema de Seguridad Pública de Catalunya; la Ley 13/2002, de 21 de junio, de turismo de Catalunya; la Ordenanza de Medidas para fomentar y garantizar la convivencia ciudadana en el espacio público de Barcelona (aprobada a 23 de diciembre de 2005 y modificada el 29 de abril de 2011); la Ley 11/2009, de 6 de julio, de regulación administrativa de los espectáculos públicos y las actividades recreativas, de Catalunya; la Ordenanza sobre el uso de las vías y los espacios públicos de Barcelona (aprobada por acuerdo del Consejo Plenario de 27 de noviembre de 1998); la Ley del Estado 1/2006, de 13 de marzo, por la que se regula el régimen especial del Municipio de Barcelona. Además, para el ejemplo ilustrativo del Distrito de Sant Martí como muestra de la "re-fronterización" urbana barcelonesa, se han añadido el Plan de veladores del eje peatonal de las calles de Rogent y Sèquia Comtal, Plaça de Font i Sagués y Rambla del Poblenou y Zonas del Distrito de análogas características (acuerdo de la Alcaldía de 3 de diciembre de 2001); el Plan Especial de establecimientos de concurrencia pública, hotelería y otros servicios del Distrito de Sant Martí (de 21 de julio de 2006); las Normas Urbanísticas de Modificación del Plan Especial de Protección del patrimonio del patrimonio arquitectónico, histórico y artístico de la ciudad de Barcelona, Distrito de Sant Martí (acuerdo del Consejo Plenario de 26 de mayo de 2000, modificado a 24 de noviembre de 2006 y a 1 de octubre de 2010); finalmente, la Modificación del Plan General Metropolitano (MPGM) en el ámbito del Casco antiguo de Poblenou (iniciado con la propuesta del 22@, en mayo de 2000, y consolidado por acuerdo de 26 de febrero de 2010.

${ }^{7}$ Es conveniente matizar que el análisis histórico del discurso observa "cómo determinados asertos vienen a constituir objetos y sujetos [...] explorados en su contexto histórico" (Denzin y Lincoln, 2005: 871), mientras que el análisis categorial establece pares categóricos textuales con el fin de codificar lo analizado e identificar las características retóricas del discurso legal a través de las cuales se construyen o reafirman distintos procesos sociales (Denzin y Lincoln, 2005: 830; Silverman, 2004: 123), como sucede en este caso con la higiene y el civismo. Para un desarrollo de la comparación, véase Denzin y Lincoln (2005: 870-874). 
lado las constantes negociaciones y contestaciones que se producen alrededor de las mismas $^{8}$.

\subsection{El "modelo Barcelona": metrópolis global}

Anteriormente se señalaba la importancia del turismo y los eventos internacionales en la representación o imagen cartográfica global de Barcelona. A partir de los Juegos olímpicos, las políticas urbanas se transforman, e impulsadas por lo que se conoció como "espíritu olímpico" y la masificación del turismo, muchas de las subsiguientes normativas irán encaminadas cada vez más al turismo, el ocio o el consumo cultural, aunque incorporando de manera progresiva enfoques desde otras escalas de imaginación política.

Con la designación de la ciudad como sede olímpica en 1986, la planificación urbana dio un importante giro que no se centraría en los productos culturales y las imágenes-ciudad hasta unos años más tarde ${ }^{9}$, aunque lo haría ya mirando a su opción de convertirse en "urbe global". Así, la Ley 22/1998, de 30 de noviembre, de la Carta Municipal de Barcelona, establece en su preámbulo la condición de Barcelona como "ciudad de convivencia, hecha en la pluralidad y diversidad, que ha proyectado al mundo su vocación de modernidad y compromiso basado en el respeto (...). Cuña de culturas que ha sido y quiere ser un ejemplo en la defensa de los derechos humanos y los pueblos".

Esa defensa de la proyección internacional de la ciudad se hacía de modo simultáneo al reconocimiento legal del estímulo de productos culturales, locales o "singulares" aun en clave de promoción global (arts. 113-117) ${ }^{10}$.

No obstante, la capital catalana se erige como símbolo definitivo de la región, en parte del Estado y parcialmente de la UE con la Ley 13/2002, de Turismo, de Cata-

\footnotetext{
${ }^{8}$ Existen importantes contestaciones de la imaginación institucional, como los modos de imaginar la ciudad a partir de las prácticas cotidianas o las formas de acción colectiva desplegadas por distintos movimientos vecinales de la ciudad. Debido a que es imposible recoger todas las visiones desde el enfoque adoptado, el presente artículo se centra en las perspectivas institucionales, aun a riesgo de eludir otras formas de imaginar y cartografiar la ciudad.

${ }_{9}^{9}$ En ese momento, fueron el MPGM y el Plan Especial de Ordenación Urbana de la Fachada al mar de Barcelona en el sector del Paseo de Carlos I y la avenida de Icaria, en 1986, así como con la MPGM en el sector del Frente Marítimo del Poblenou de 1993.

${ }^{10}$ Hay que considerar que el contexto del momento suponía el enfrentamiento de distintas posturas acerca del "patrimonio cultural" de la ciudad, que abarcaba desde reivindicaciones locales (de distrito y de barrio) por el patrimonio fabril hasta la regulación municipal y autonómica de la industria como "signo" de la ciudad y de Catalunya (Tatjer, 2008). Al mismo tiempo, si bien es cierta la "tradición" barcelonesa por albergar Ferias y Exposiciones Internacionales desde finales del siglo XIX, la cuestión esencial es la referencia "global" de los eventos internacionales, no si su celebración implica la mera colaboración más allá de las fronteras del Estado.
} 
lunya, con la que la ciudad aparece a la cabeza de una supuesta tradición histórica de turismo y proyección mundial. Además, dentro de esa promoción, las ciudades y los espacios urbanos irrumpen como elementos protagonistas y, por ende, son reconocidos como nodos o contenedores de recursos turísticos esenciales (art. 5). Aunque se habilitan otros territorios como espacios turísticos (comarcas), tanto el refuerzo a los Ayuntamientos urbanos (art. 66.1.b) como la atención prestada a los municipios turísticos y las áreas urbanas privilegiadas (arts. 18-22), aunado al privilegio reconocido a Barcelona en el liderazgo regional, dotó a la Ciudad Condal de una posición preeminente de cara a la imaginación turística global.

Igualmente, la consolidación de la posición de la ciudad en las distintas estructuras de las redes urbanas internacionales (como Eurocities) o la proyección de algunos elementos de su planificación urbanística implicó una movilidad del "modelo Barcelona" que no tenía parangón en el contexto español (González, 2011).

Se iba gestando la imagen de una ciudad "orientada al exterior", moderna, turística y en vías de globalización no sólo a través de las distintas formas de estandarizar singularidades locales o de urbanalizar (Degen, 2010; Muñoz, 2008, 2010) y hacer viable el empresarialismo urbano (Harvey, 2007), sino por una intervención directa de las instituciones públicas en el fomento de la internacionalización y la promoción de la ciudad.

2.2. "Barcelona, iponte guapa! (y límpiate)". El retorno al higienismo y el civismo como geografía moral de la ciudad

El higienismo como eje de la planificación urbana ha estado presente desde finales del siglo XIX, especialmente a partir de la restructuración emprendida por Haussman en los bulevares de París (Soja, 2008). Lo que más tarde se conoció como haussmanización consistía en principio en la construcción de amplios bulevares transversales a los ejes de la ciudad y tenían un carácter esencialmente represor. Más tarde, la "claridad" e iluminación de determinadas zonas grises de la ciudad devino control institucional progresivo, legitimado por la construcción de cartografías del miedo (Lindón, 2007).

En el caso de Barcelona, el higienismo data de finales del siglo XIX, especialmente a partir del Plan Cerdá (Delgado, 2007), y su recuperación se produce de manera progresiva desde finales de los años 1980, convergiendo con el civismo de los noventa como uno de los discursos de mayor calado en la redefinición de la ciudad. A partir de las campañas de promoción institucional, la retórica oficial recogida en la legislación o las ordenanzas cívicas, se generó un efecto prescriptivo sobre los ámbitos urbanos en la medida en que "recuerdan un uso correcto del espacio, así como limitan el mismo a una única forma de usarlo que sirve tanto para que un ciudadano «normal» entienda que un banco es para sentarse [...] como para 
restringir todo uso del espacio público que no reciba autorización" (Martínez Lorea, 2010: 9).

A finales de 1998 aparecía una concentración de la retórica sobre la higiene urbana y la tolerancia cívica en los espacios de la ciudad ${ }^{11}$. La razón no era otra que la supuesta "escasez y limitación de los usos de los espacios públicos", que iban desplazándose hacia el tránsito de gente o el intercambio mercantil, más que a una zona de reunión colectiva.

El énfasis en "la tolerancia, el civismo y la convivencia pacífica barcelonesa" (Delgado, 2007) se consolidaba con lo generado por la normativa: se produjo un endurecimiento de las infracciones relativas al civismo o el tránsito sobre los ámbitos urbanos ${ }^{12}$, así como se reforzó la responsabilidad individual en los mecanismos disciplinares de la higiene urbana (art. 21.11 y art. 63.2.a), pero fueron suprimidas otras formas de sancionar acciones colectivas directas ${ }^{13}$.

Ese "deber cívico" en el espacio público se refuerza en la Ordenanza de Medidas para fomentar y garantizar la convivencia ciudadana en el espacio público de Barcelona de 2005 (en adelante, Ordenanza Cívica de Barcelona), tanto en las prohibiciones crecientes sobre el uso del mismo, como en un deber de "uso correcto" del espacio público de la ciudad (art. 6.4), evitando la irresponsabilidad de la ciudadanía (art. 7.2.b) o las conductas que afecten a la convivencia ciudadana en el espacio público $^{14}$.

Más aún, civismo e higiene se van imponiendo como prácticas "normales" del espacio urbano hasta el punto de articularse como un comportamiento contrario al peligro, la incomodidad o el riesgo públicos ${ }^{15}$. Y lo que es más importante, ambos elementos se consolidan como ejes de la regulación de un espacio público concebido como algo desprovisto de conflicto. Procesos sociales estructurales plenamente políticos como la manifestación, la asociación, el comercio informal, la mendicidad o la prostitución son excluidos progresivamente del espacio público a partir de principios de salubridad (art. 42-52), de estética urbana (art. 19.3), de higiene

\footnotetext{
${ }^{11}$ Exposición de motivos de la ordenanza sobre el uso de las vías y los espacios públicos de Barcelona, aprobada por acuerdo del Consejo Plenario de 27 de noviembre de 1998.

${ }^{12}$ Desde sancionar "actos perturbadores de la tranquilidad vecinal" (art. 10.3) hasta ocupar espacios públicos no transitados (art. 63.4. e).

${ }^{13}$ Se derogan algunos artículos relativos a la libertad de expresión y propaganda pública (art. 63.1.c, d, e y g), mientras se reducían a infracción leve otras formas de usar el espacio público (art. 67.2.b y c).

${ }_{15}^{14}$ Hasta el punto de restringir la prostitución por una cuestión de "molestias" en el mismo.

${ }^{15}$ Artículo 5.2.c de la Ley 11/2009, de 6 de julio, de regulación administrativa de los espectáculos públicos y las actividades recreativas, que considera la importancia del ocio, el arte o la cultura en el marco de hacer del espacio público un "lugar de convivencia y civismo [...], libre circulación, ocio, encuentro y recreo" (exposición de motivos).
} 
política (art. 19-20) o, sobre todo, de "pertinencia de los usos del espacio público" (art. 57-65 $5^{16}$ ).

Así, la forma de articular el espacio público barcelonés desde el civismo dibujaba un mapa de la ciudad representado por una parte por los eventos, monumentos y acontecimientos de importancia global que se desarrollaban en la ciudad y, por otro, por un espacio urbano que eliminaba la discrepancia, los elementos conflictivos o que incluso normalizaba la higiene cívica como "deber ser" de la ciudad. Así, no sólo a través del control del espacio público, sino de diferentes campañas publicitarias, el territorio se subsume en una visión de desplazamiento y en función de los espacios producidos, identificándose una imaginación geográfica donde el paisaje urbano aparece como algo "limpio, cívico y ordenado" (Lindón, 2007), sujeto a control institucional y a una estética de orden público (Mitchell, 2007).

El corolario será el Plan General de Seguridad para Cataluña 2012-2013, según el cual la Administración se compromete a desarrollar una ley de ordenación del espacio público y otra de espectáculos y actividades recreativas a través de las que los ámbitos urbanos adaptarán el marco legal a las demandas de seguridad "sin dañar la convivencia cívica ni la proyección internacional de la ciudad" (Preámbulo). En el caso barcelonés, el espacio público no podrá ser objeto de conductas de grupos considerados sospechosos de irresponsabilidad con el civismo ${ }^{17}$.

Sin embargo, la abstracción y ambigüedad de la normativa relativa al higienismo y al civismo, aunado con la multiplicación de actividades desarrolladas en la ciudad, dejaba una infinidad de prácticas sociales en un limbo legal, suturado a instancias de la habilitación de políticas territoriales en la ciudad. Esta tendencia ponía de manifiesto una paradoja que se estaba produciendo en la restricción de facto del espacio público: la "pacificación forzada" del territorio barcelonés contrastaría con la creciente exclusión y parcelación del mismo a partir de las políticas de renovación urbana.

\subsection{De la higiene a la renovación urbana: territorios encontrados}

Tanto la puesta en marcha de proyectos "globales" de la ciudad (UTE, 2004; Yproductions, 2007) como la aplicación del civismo como eje estructurador de urbani-

\footnotetext{
${ }^{16}$ Además de definir lo que considera "usos impropios del espacio público", se prohíbe el deterioro del espacio urbano y se establece un catálogo flexible de "otras conductas que perturban la convivencia ciudadana" (zonas naturales y espacios verdes, playas, etc.).

${ }^{17}$ Se prevé la prohibición de cubrirse en manifestaciones (vulnerando el principio de seguridad personal y anonimato esgrimido por las Fuerzas y Cuerpos de seguridad del Estado en circunstancias similares); sanciona los "nuevos grupos de jóvenes violentos" (art. 5.1) o concede amplias potestades policiales para responder a "los cambios sociales" (objetivo estratégico número 13).
} 
dad habían supuesto una concentración de funciones en el Ayuntamiento barcelonés y un refuerzo considerable de las potestades del Alcalde ${ }^{18}$, lo que suponía una imaginación de la ciudad como algo único. No obstante, la mayoría de proyectos de imágenes ciudad se llevaron a cabo siguiendo dos directrices que redefinían la territorialidad de la ciudad ${ }^{19}$ : la espacialización de prácticas sociales y la configuración de espacios de renovación urbana.

La primera de ellas, incipiente ya en los comportamientos que se consideraban correctos y cívicos en determinados espacios urbanos, quedó consolidada con la Ley 11/2009, de 6 de julio, de regulación administrativa de los espectáculos públicos y las actividades recreativas.

Se crea una delimitación de los espacios públicos y actividades recreativas (art. 3), espacialización que converge con la prohibición de efectuar juegos en espacios públicos establecida por la Ordenanza Cívica de Barcelona en sus artículos 30-33. Quedan regulados los espacios abiertos al público (art.3.1. d), incluidos en algunos que forman parte del patrimonio socio-cultural catalán (art. 4.4). Asimismo, se obliga a promover zonas de ocio en la planificación urbana (art. 27), toda vez que el activismo es excluido de estas formas de territorialidad (art. 4.5.b) y se produce la zonificación de la congregación del público, incluyendo las áreas delimitadas permisivas de reunión (art. 5.2.a).

Las zonas de ocio y las actividades públicas quedan así sujetas a una concentración estática, desprovista de la reunión política, potencialmente ilimitada en toda la región urbana ${ }^{20}$.

Todo ello contrastaría con la segunda dinámica, la de articulación de espacios de renovación urbana.

Tras el plan de renovación residencial de1985 y después de los Juegos Olímpicos, las políticas de restructuración y gentrificación urbana se aceleraron, convirtiéndose en una directriz de la agencia institucional municipal y autonómica (Balibrea, 2004, 2007; Borja, 2009).

\footnotetext{
${ }^{18}$ Articuladas fundamentalmente en la Ley 4/2003, de 7 de abril, de Ordenación del Sistema de Seguridad Pública de Cataluña (art. 9); la Ley del Estado 1/2006, de 13 de marzo, por la que se regula el régimen especial del municipio de Barcelona (arts. 6-16 y Disposición adicional Quinta); y la Ley 11/2009, de 6 de julio, de regulación administrativa de los espacios públicos y actividades recreativas (arts. 13, 39 y Disposición adicional segunda).

${ }^{19}$ La territorialidad es "aquella conducta que trata de influir, controlar o afectar el control limitado de un espacio y sus recursos" (Sack, 1983: 55). Las políticas territoriales urbanas vienen de lejos, sobre todo por lo que se refiere a las políticas de policía (Herbert, 2010) y la prohibición de uso de determinados lugares para actividades concretas.

${ }^{20}$ La disposición adicional segunda establece un Régimen Especial del municipio de Barcelona que "atribuye al Ayuntamiento la competencia para autorizar la instalación o apertura de todo tipo de establecimientos abiertos al público y de actividades en dicha ciudad".
} 
La Ley 2/2004, de 4 de junio, de mejora de barrios, áreas urbanas y villas que requieren una atención especial, recogía la degradación histórica de determinadas zonas así como reconocía la reestructuración urbana como la solución a la reducción del bienestar y de la cohesión social (preámbulo de la ley). Se establece la rehabilitación y promoción urbanas como elementos prioritarios en la financiación autonómica (arts. 1 y 6), y fija una renovación completa de tales lugares en clave de innovación como objetivo a desarrollar ${ }^{21}$, incluyéndose dentro del planeamiento de la ciudad a partir de 2010 como territorios potenciales de la ciudad ${ }^{22}$.

Dentro de estas zonas de renovación urbana destaca el caso del Distrito de Sant Martí como ejemplo paradigmático de esta territorialización de la ciudad. Tras las MPGM en el Frente Marítimo del Poblenou (1993) y en el Sector del Front Litoral i Marge del riu Besòs (2000), se emprendió la renovación de un urbanismo industrial que se consideraba obsoleto. Después de las reivindicaciones vecinales por el reconocimiento del patrimonio industrial como elemento inherente al barrio (Marrero Guillamón, 2003), la Modificación del Plan Especial de protección del patrimonio arquitectónico, histórico y artístico de la ciudad de Barcelona en el Distrito de Sant Martí sentó las bases para el establecimiento de nuevas territorialidades que cuestionaban los espacios históricos, fundamentalmente a través del llamado Plan 22@ (Rojas et al., 2007).

E122@era un proyecto de renovación sectorial y territorial de la mayoría de los anteriores espacios fabriles de Poblenou, el histórico barrio industrial barcelonés (Tatjer, 2008). Ello suponía un desplazamiento de las centralidades espaciales barriales hacia sectores de innovación y áreas renovadas que tenían un tratamiento específico, como el sur de la Avenida Diagonal o las áreas de Diagonal Mar, la Plaza de les Glòries o la del Fórum (art. 7.4). Pero además implicaba, por parte de la Administración Local, un reto a las prácticas locales por la vía del reconocimiento de actividades "populares no autónomas" (arts. 4.2.5.3 y 4) y, sobre todo, mediante la reformulación de las espacialidades “oficiales", ya que el 22@ no agrupaba ni Poblenou ni Sant Martí, sino que constituía un espacio distinto definido por las nuevas inversiones en innovación y economía del conocimiento (Dot Jutgla et al., 2010; Martí-Costa y Pradel i Miquel, 2012).

Donde antes se reconocían bienes locales relevantes o incluso culturales, ahora aparecían desplazados por los de relevancia "sectorial" (art. 8.2.c) o los entornos que participan de la memoria histórica de la ciudad (art. 10.3.a).

Con el Fórum de las Culturas celebrado en 2004 y el Plan Especial de concurrencia pública, hostelería y otros servicios del Distrito de Sant Martí (aprobado a

\footnotetext{
${ }^{21} \mathrm{El}$ artículo 7.2 establece entre ellos la incorporación de las nuevas tecnologías de información y comunicación a las edificaciones o la sostenibilidad urbana.

${ }^{22}$ Artículos 3.2, 9.3, 70 y 71 del Decreto legislativo 1/2010, de 3 de agosto, por el que se aprueba el texto refundido de la ley de urbanismo.
} 
21 de julio de 2006), esos espacios diferenciales se fueron moviendo hacia la Villa olímpica, el nuevo Diagonal Mar y la Zona Fórum, sin olvidar el complejo 22@. Lo que habían sido intentos por definir la ciudad como un espacio público común, unitario e internacional quedaba ahora redefinido por nuevas espacialidades a nivel interno que imponían una segregación territorial basada en el reconocimiento formal de una renovada Barcelona, enfrentada a los espacios informales de la "vieja" barriada industrial.

De esta forma, las tres tendencias anteriormente identificadas trazan una imaginación geográfica construida en Barcelona en las dos últimas décadas basada en la orientación exterior, la higiene, la renovación zonal y el civismo como claves explicativas del mapa urbano.

El "símbolo de libertad, progreso, convivencia, pluralidad, diversidad, proyección e iniciativa internacionales, tolerancia, solidaridad, paz y crisol cultural ${ }^{23}$ " en que se convertía Barcelona según la legislación contrastaba con una producción normativa de la geografía de la ciudad que suprimía las prácticas informales de manera progresiva del espacio público, así como se somete a excepción el uso colectivo del espacio público ${ }^{24}$, aplastado por la normalización del mismo basada en el uso transitorio, cívico y la renovación e higiene urbana.

Por otro lado, las políticas de renovación y territorialización urbanas han parcelado las espacialidades oficiales hasta ser definidas por razones sectoriales que, en última instancia, son dependientes del ámbito institucional y de las imágenes de proyección exterior, habilitando la estructuración y reproducción de diferentes regiones de frontera en la ciudad delimitadas por esos itinerarios de separación (interior) y contacto (exterior) dibujados por los proyectos de renovación, gentrificación y espacialización de actividades en la ciudad.

\section{Conclusión: Barcelona, ¿región de frontera?}

A lo largo de este artículo y partiendo del enfoque de la Geografía crítica del derecho, he analizado algunas de las prácticas políticas que desde la regulación normativa institucional han trazado un imaginario geográfico acerca del espacio público en Barcelona, así como sus influencias en la reformulación del mismo.

\footnotetext{
${ }^{23}$ Exposición de motivos de la Ley del Estado 1/2006, de 13 de marzo, por la que se regula el régimen especial del municipio de Barcelona.

${ }^{24}$ Las primeras por la vía de los artículos 21 y 70 de la Ordenanza sobre los usos de las vías y espacios públicos de Barcelona de 1998. En cuanto al espacio público, se denomina "uso común especial" a aquel que somete la vía pública a especial intensidad, ocupación transitoria (art. 27), entre los que destacan los supuestos de "celebración de actos públicos, la acampada en los espacios públicos o en vehículos estacionados en éstos [...], la publicidad manual u oral" (art. 28.1.e, f y g).
} 
Las tendencias hacia el civismo, el higienismo, la renovación y la gentrificación zonal, o la creación de imágenes globales de la ciudad han producido desde el ámbito normativo la irrupción de regiones de frontera en Barcelona, aunque a la inversa de los paisajes del miedo. En lugar de establecer límites internos basados en una imaginación territorial definida por el riesgo, lo que construyen estas regiones de frontera son nuevas espacialidades de la ciudad representadas por una mirada al exterior y por su condición de áreas de innovación, renovación, convivencia y civismo urbano, con independencia de lo que representen otros espacios cotidianos distintos, ensombrecidos o invisibilizados precisamente por no ser objeto de las prácticas anteriormente expuestas o por haber sido reconfigurados por las vías de territorialización formal (como el 22@) o informal (como la Zona Fórum).

La paradoja es doble: mientras la retórica hace alusión al espacio de la ciudad como un todo, las políticas de renovación y representación territorial se articulan desde espacios e imaginarios singulares, regiones de frontera particulares de la ciudad, estructurando nuevos modos de espacialidad que se encuentran con una proyección constante de la ciudad a modo de región de frontera entre los proyectos internacionales, renovación, planificación y diseño urbano, por un lado, y otros espacios urbanos cuya atención queda desplazada u oculta por la imaginación geográfica que proyectan las dinámicas anteriores. O sea, una zona de contacto entre dos tipos de procesos socio-espaciales (o momentos) distintos.

Pero, al mismo tiempo que esta imaginación geográfica de la ciudad es construida desde las instancias institucionales, se dan contestaciones cotidianas a través de la producción diferencial de espacios alternativos y múltiples ${ }^{25}$, oponiendo a la ciudad concebida una (o múltiples) ciudad practicada (Delgado, 2006). Pero eso es materia para otro artículo.

\section{Bibliografía}

Agnew, J., y Duncan, J. (1989) The power of place: bringing together geographical and sociological imaginations. Boston-Londres: Unwin Hayman.

\footnotetext{
${ }^{25}$ Como son la organización barrial del $15 \mathrm{M}$ o diversas Asociaciones de vecinos. Un ejemplo ilustrativo es el Consorcio del barrio de La Mina, así como las actuaciones conjuntas con la Asociación de vecinos de La Mina-Sant Adrià del Besòs. Mientras el resto de Asociaciones de vecinos del distrito de Sant Martí se oponían al proyecto del Fòrum de las Culturas y el Consorcio barcelonés lo diseñaba como una gran muestra del multiculturalismo de Barcelona, dicha asociación defendía la construcción del Recinto Fórum como una forma de renovación particular del barrio, con independencia de las críticas vertidas por otras asociaciones vecinales o del diseño urbano conjunto que hacía el Ayuntamiento barcelonés. Véase URL: $<$ http://www.barrimina.cat/cast/index.php/plan-de-transformaciainmenu-39/urban-mainmenu-48/pic-urban-ii -sac-la-mina-mainmenu-49.html $>$ [consultado a 19 de mayo de 2012].
} 
Aramburu, M. (2008) "Usos y significados del espacio público". ACE, Arquitectura, ciudad y entorno, vol. $3, \mathrm{n}^{\circ} .8,143-151$.

Balibrea, M. P. (2007) "La marca y el pasado: estrategias de lucha por el espacio social en la Barcelona posindustrial", en Yproductions (ed.) Producta50. Una introducción a las relaciones entre economía y cultura. Barcelona: Generalitat de Catalunya, 20-35.

Balibrea, M. P. (2004) "Barcelona: del modelo a la marca", [URL: $<$ http://www.arteleku.net/vieja/desacuerdos/index.jsp>. Consultado el $12 \mathrm{de}$ Enero de 2012].

Barkan, J. (2011) "Law and the geographic analysis of economic globalization". Progress in Human Geography, vol. 35, no. 5, 589-607.

Blomley, N. (2010) "The right to pass freely: circulation, begging and the bounded itself". Social and Legal Studies, vol. 19, nº. 3, 331-350.

Blomley, N. (2008) "Making space for law", en K. Cox, M. Low y J. Robinson (eds.) The Sage Handbook of political geography. Londres-Thousand OaksNueva Delhi: Sage, 155-168

Blomley, N. (2004) "Un-real estate: proprietary space and public gardening". Antipode, vol. 36, $\mathrm{n}^{\mathrm{o}}$. 4, 614-641.

Blomley, N. (2003) "Law, property and the spaces of violence". Annals of the Association of American Geographers, vol. 93, $\mathrm{n}^{\circ} .1,121-141$.

Borja, J. (2009) Luces y sombras del urbanismo de Barcelona. Barcelona: Ediciones UOC.

Brenner, N. (2004) New states spaces: urban governance and the rescaling of statehood. Nueva York: Oxford University Press.

Checa Artasu, M. M. (2007) "Geografías para el patrimonio industrial en España: el caso de Barcelona". Scripta Nova, Revista electrónica de Geografía y Ciencias Sociales, vol. XI, nº 245 (32) [Puesto en línea el 1 de Agosto de 2007. URL: $<$ http://www.ub.edu/geocrit/sn/sn-24532.htm $>$. Consultado el 24 de Febrero de 2012].

Chouliaraki, L. y Fairclough, N. (1999) Discourse in late modernity: rethinking critical discourse analysis. Edimburgo: Edinburgh University Press.

Dangschat, J. S. (2009) "Space matters. Marginalization and its places". International Journal of Urban and Regional Research, vol. 33, $\mathrm{n}^{\circ} .3,835-840$.

Degen, M. (2010) "Consuming urban rhythms: let's ravalejar", en T. Edensor (ed.) Geographies of rhythm. Aldershot: Ashgate, 21-31.

Degen, M., y García, M. (2008) La metaciudad: Barcelona, transformación de una metrópolis. Barcelona: Anthropos.

Delaney, D.; Blomley, N., y Ford, R. T. (2001) “Where is law?”, en N. Blomley, D. Delaney y R. T. Ford (eds.) The legal geographies reader: law, power and space. Oxford: Blackwell, xiii-xxii.

Delgado, M. (2007) La ciudad mentirosa. Fraude y miseria del "modelo Barcelona". Madrid: Catarata. 
Delgado, M. (2006) "De la ciudad concebida a la ciudad practicada". Archipiélago, $n^{\circ} .62,7-12$.

Delgado, M. (2005) Elogi del viandant. De la Barcelona model a la Barcelona real. Barcelona: Edicions de 1984.

Denzin, N., y Lincoln, Y. (2005) The Sage Handbook of qualitative research. Londres-Thousand Oaks-Nueva Delhi: SAGE.

Dot Jutgla, E; Casellas, A., y Pallarès-Barbera, M. (2010) "L'ambigüitat de la producció intensiva en coneixement: el nou espai econòmic del Poblenou". Documentos de Anàlisis Geogràfica, vol. 56, nº . 3, 389-408.

Featherstone, M., y Lash, S. (eds.) (1999) Spaces of culture. Londres-Thousand Oaks-Nueva Delhi: Sage.

Forest, B. (2004) "The legal (de) construction of geography: race and political community in Supreme Court redistricting decisions". Social and Cultural Geography, vol. 5, $\mathrm{n}^{\mathrm{o}}$. 1, 55-73.

Forest, B. (2001) "Mapping democracy: racial identity and the quandary of political representation". Annals of the Association of American Geographers, vol. 91, $\mathrm{n}^{\circ}$. 1, 143-166.

González, S. (2011) "Bilbao and Barcelona «in motion». How urban regeneration "models" travel and mutate in the global flows of policy tourism". Urban Studies, vol. 48, $\mathrm{n}^{\circ} .7,1397-1418$.

Gregory, D.; Johnston, R.; Pratt, G.; Watts, M. J., y Whatmore, S. (eds.) (2009) Diccionary of Human Geography. Malden-Oxford-West Sussex: BlackwellWiley ( $5^{\mathrm{a}}$ ed).

Habermas, J. (1974) "The public sphere: an encyclopedia article". New German critique, 3, 49-55.

Harvey, D. (2007) Espacios del capital. Madrid: Akal.

Herbert, S. (2010) "Contemporary geographies of exclusion III: to assist or punish?". Progress in Human Geography, vol. 35, n. 2, 256-263.

Johnston, R. J.; Gregory, D., y Smith, D. (2000) Diccionario Akal de Geografía humana. Madrid: Akal.

Johnston, R. J.; Taylor, P. J., y Watts, M. (eds.) (2002) Geographies of global change: remapping the world. Malden-MA: Blackwell.

Judge, D.; Stoker, G. y Wolmann, H. (eds.) (1998) Theories of urban politics. London: SAGE.

Knox, P.; Agnew, J. y McCarthy, L. (eds.) (2003) The geography of the worldeconomy. Londres: Edward Arnold.

Lefebvre, H. (1976) Espacio y política: el derecho a la ciudad II. Barcelona: Península.

Lindón, A. (2007) "La construcción social de los paisajes del miedo", en J. Nogué (ed.) (2007) La construcción social del paisaje. Madrid: Biblioteca Nueva, 213236.

Low, S., y Smith, N. (2006) The politics of public space. New York: Routledge. 
Marrero Guillamón, I. (2003) “¿Del Manchester catalán al Soho barcelonés? La renovación del Poblenou en Barcelona y la cuestión de la vivienda". Scripta Nova, Revista electrónica de Geografía y Ciencias Sociales, vol. VII, nº 146 (137) [Puesto en línea el 1 de agosto de 2003. URL: $<$ http://www.ub.edu/geocrit/sn/sn-146(137).htm>. Consultado el 13 de febrero de 2012].

Martí-Costa, M. y Pradel i Miquel, M. (2012) “The knowledge city against urban creativity? Artists' workshops and urban regeneration in Barcelona". European Urban and Regional Studies, vol. 19, $\mathrm{n}^{\circ} .1,92-108$.

Martin, D.; Scherr, A. W., y Christopher City (2010) "Making law, making place: lawyers and the production of space". Progress in Human Geography, vol. 34, $\mathrm{n}^{\mathrm{o}} .2,175-192$.

Martínez Lorea, I. (2010) "El papel del civismo en la recuperación de los centros históricos", en Actas del X Congreso Español de Sociología [URL: $<$ http://www.fes-web.org/archivos/congresos/congreso_10/grupostrabajo/ponencias/713.pdf $>$. Consultado el 21 de Marzo de 2012].

Mitchell, D. (2007) "Muerte entre la abundancia: los paisajes como sistemas de reproducción social", en J. Nogué (ed.) (2007) La construcción social del paisaje. Madrid: Biblioteca Nueva, 85-110.

Mitchell, D. (2003) "The liberalization of free speech: or, how protest in public space is silenced", Stanford Agora. [URL: <http://agorastandford.edu/agora/volume4/articles/mitchell/mitchell.pdf $>$. Consultado el 13 de Diciembre de 2011].

Mitchell, D. (1997) "The annihilation of the space by law: the roots and implications of anti-homeless laws in United States". Antipode, vol. 29, $\mathrm{n}^{\circ} .3,303-335$.

Mitchell, D., y Heynen, N. (2009) "The geography of survival and the right to the city: speculations on surveillance, legal innovation and the criminalization of intervention". Urban Geography, vol. 30, n. 6, 611-632.

Mitchell, D., y Staeheli, L. (2005). "Permitting protest: parsing the fine geography of dissident in America". International Journal of Urban and Regional Research, vol. $29, \mathrm{n}^{\circ} .4,796-813$.

Muñoz, F. (2010) "Contra la urbanalització: de la ciutat post-it a la ciutat pòsit". Revista del Centre d'Estudis Jordi Pujol, vol. 12, 189-200.

Muñoz, F. (2008) UrBANALización: paisajes comunes, lugares globales. Barcelona: Gustavo Gili.

Pitkin, H. F. (1985) [1967] El concepto de representación. Madrid: Centro de Estudios Constitucionales.

Poggi, G. (1977) "The constitucional State of the Nineteenth Century: an elementary conceptual portrait". Sociology, vol. 11, 311-332.

Rojas, J.; Pellicer, I.; Santoro, V., y Vivas, P. (2007) “@City: lecturas tecnológicas de Barcelona". Athenea Digital, $\mathrm{n}^{\circ}$. 11, 114-131. 
Sack, R. (1983) "Human territoriality: a theory". Annals of the Association of American Geographers, vol. 73, n'. 1, 55-74.

Salcedo, M., y Caicedo, S. (2008) "El espacio público como objeto de estudio en las Ciencias Sociales y humanas". Revista Cientifica Guillermo de Ockham, vol. 6, $\mathrm{n}^{\circ} .1,99-115$.

Silverman, D. (2004) Interpreting qualitative data: methods for analysing talk, text and interaction. Londres: Sage.

Smith, N. (1996) The new urban frontier. Gentrification and the revanchist city. Londres-Nueva York: Routledge.

Soja, E. W. (2008) Postmetrópolis. Estudios críticos de ciudades y regiones. Madrid: Traficantes de Sueños.

Staeheli, Lynn A. (2010) "Political geography: democracy and the disorderly public". Progress in human geography, vol. 34, no. 1, 67-78.

Tatjer, M. M. (2008) "El patrimonio industrial de Barcelona entre la destrucción y la conservación, 1999-2008". Scripta Nova. Revista Electrónica de Geografia y Ciencias Sociales, vol. XII, ${ }^{\circ}$. 270 (140) [Puesto en línea el 1 de Agosto de 2008. URL: <http://www.ub.edu/geocrit/sn/sn-270/sn-270-140.htm>. Consultado el 1 de Noviembre de 2011].

Taylor, P., y Flint, C. (2002) Geografía política: Economía-mundo, Estado-nación y localidad. Madrid: Trama.

Tresserras, J. J. (2004) "La tematización de las ciudades: el uso de la cultura en las estrategias de desarrollo local y promoción del turismo urbano". Anuario Turismo y Sociedad, vol. 5, nº. 3, 71-85.

UTE (2004) Barcelona: marca registrada. Un model per desarmar. Barcelona: Virus.

Young, I. M. (1990) Justice and the politics of difference. Princeton (NJ): Princeton University Press.

Yproductions (ed.) (2007) Producta50. Una introducción a las relaciones entre economía y cultura. Barcelona: Generalitat de Catalunya. 